\title{
Endovascular Treatment of Intracranial Aneurysms with the WEB Device: A Systematic Review of Clinical Outcomes
}

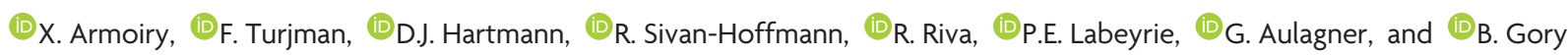

\begin{abstract}
BACKGROUND AND PURPOSE: Despite the improvement in technology, endovascular treatment of bifurcation intracranial wide-neck aneurysms remains challenging, mainly due to the difficulty of maintaining coils within the aneurysm sac without compromising the patency of bifurcation arteries. The Woven EndoBridge (WEB) device is a recent intrasaccular braided device specifically dedicated to treating such aneurysms with a wide neck by disrupting the flow in the aneurysmal neck and promoting progressive aneurysmal thrombosis.
\end{abstract}

MATERIALS AND METHODS: Using several health data bases, we conducted a systematic review of all published studies of WEB endovascular treatment in intracranial aneurysms from 2010 onward to evaluate its efficacy and safety profile.

RESULTS: The literature search identified 6 relevant studies (7 articles) including wide-neck bifurcation aneurysms in $\geq 80 \%$ of cases. Clinical data supporting the efficacy and safety of the WEB are limited to noncomparative cohort studies with large heterogeneity from a methodologic standpoint. The WEB deployment was feasible with a success rate of $93 \%-100 \%$. Permanent morbidity (mRS of $>1$ at last follow-up) and mortality were measured at $2.2 \%-6.7 \%$ and $0 \%-17 \%$, respectively. The adequate occlusion rate (total occlusion or neck remnant) varied between $65 \%$ and $85.4 \%$ at midterm follow-up (range, 3.3-27.4 months).

CONCLUSIONS: Endovascular treatment of bifurcation wide-neck aneurysms with the WEB device is feasible and allows an acceptably adequate aneurysm occlusion rate; however, the rate of neck remnants is not negligible. The WEB device needs further clinical and anatomic evaluation with long-term prospective studies, especially of the risk of WEB compression. Prospective controlled studies should be encouraged.

ABBREVIATIONS: $\mathrm{CE}=$ Conformité Européenne; PRISMA = Preferred Reporting Items for Systematic Reviews and Meta-Analyses; WEB = Woven EndoBridge; WEB-DL = Woven EndoBridge Dual-Layer; WEB-SL = Woven EndoBridge Single-Layer; WEB-SLS = Woven EndoBridge Single-Layer Sphere

W ith the emergence of detachable coils and results of the International Subarachnoid Aneurysm Trial and Barrow Ruptured Aneurysm Trial, ${ }^{1,2}$ endovascular coiling has become the first-line option for ruptured intracranial aneurysms. It is also a widely accepted option for unruptured aneurysms

Received September 8, 2015; accepted after revision October 8.

From the Délégation à la Recherche Clinique et à l'Innovation (X.A.), Hospices Civils de Lyon, Cellule Innovation, Lyon, France; CNRS 5510/MATEIS (X.A., D.J.H., P.E.L., G.A.), Lyon, France; Service de Neuroradiologie Interventionnelle (F.T., R.S-H., R.R., B.G.), DHU IRIS, Hôpital Neurologique Pierre Wertheimer, Hospices Civils de Lyon, Lyon, France; Université Lyon 1 (F.T., D.J.H., G.A., B.G.), Lyon, France; Centre de Neurosciences Cognitives (F.T., B.G.), CNRS, UMR 5229, Lyon, France; Galilee Medical Center (R.S.-H.), Nahariya, Israel; Serine Proteases and Pathophysiology of the Neurovascular Unit (P.E.L.), INSERM UMR-S U919, Caen, France; and Service Pharmaceutique (G.A.), Hospices Civils de Lyon, Groupement Hospitalier Est, Lyon, France.

Please address correspondence to Benjamin Gory, MD, MSc, DHU IRIS, Department of Interventional Neuroradiology, Hospices Civils de Lyon, Hôpital Neurologique Pierre Wertheimer, 59 Boulevard Pinel, 69677 Bron, France; e-mail: benjamin.gory@chu-lyon.fr

三 Indicates article with supplemental on-line table.

http://dx.doi.org/10.3174/ajnr.A4611 that are anatomically suitable for endovascular approaches. ${ }^{3}$ However, coiling of large and wide-neck intracranial aneurysms is associated with low initial complete obliteration, a high incidence of recanalization (up to $20 \%$ at 12 months), and a $10 \%$ rate of retreatment. ${ }^{4}$ Promising technologies like flowdiverter stents have the potential to overcome some of the limitations of standard coiling for sidewall aneurysms, ${ }^{5-7}$ but the management of large wide-neck bifurcation aneurysms remains challenging. Balloon and stent-assisted techniques have widened the indications for endovascular treatment of aneurysms with a wide neck and/or unfavorable anatomy that were otherwise unsuitable for coiling. ${ }^{8-10}$ However, endovascular treatment of such complex intracranial aneurysms requires the use of complex endovascular techniques with double-stent placement in $\mathrm{Y}$ and $\mathrm{X}$ configurations. Bartolini et $\mathrm{al}^{11}$ suggested that $\mathrm{Y}$ and $\mathrm{X}$ stent-assisted coiling was associated with a high rate of complications, $10 \%$ procedure-related permanent morbidity, and $1 \%$ mortality rate.

In this context, a new endovascular device, the intrasaccular 
flow disruptor Woven EndoBridge (WEB; Sequent Medical, Aliso Viejo, California), specifically designed to treat wide-neck bifurcation intracranial aneurysms, has emerged in the past 5 years. ${ }^{12-14}$ There is an emerging body of literature on the use of the WEB device, but to our knowledge, no study has specifically reviewed the evidence on its use. We, therefore, performed a literature review of this technique in the management of wide-neck bifurcation intracranial aneurysms. Our specific aims were to evaluate its feasibility, safety, and effectiveness to finally discuss its place in the endovascular treatment of bifurcation intracranial aneurysms.

\section{MATERIALS AND METHODS Description of the WEB Device}

The Woven EndoBridge system, known as the WEB aneurysm embolization system, is a self-expanding, oblate, braided nitinol mesh deployed in the aneurysm sac. The WEB device was originally released under a Dual-Layer configuration (WEBDL) in which the first nitinol cage contains a proximally placed second nitinol braid. The inner and outer braids are made of 108 or 144 extremely fine nitinol wires (diameters from 19 to $38 \mu \mathrm{m})$. Therefore, the WEB-DL device has a total of 216 or 288 wires responsible for the intrasaccular blood flow disruption. The WEB-DL is available in several diameters (from 5 to $11 \mathrm{~mm}$ ) and lengths (from 3 to $9 \mathrm{~mm}$ ). Recently, the WEB device has evolved into a Single-Layer version (WEB-SL and Single-Layer Sphere [WEB-SLS]) not containing any inner braid. The WEB-SL has a higher number of nitinol wires (from 144 for the $4-\mathrm{mm}$ diameter to 216 for the $11-\mathrm{mm}$ diameter) providing a blood flow disruption while maintaining radial force. The WEB-SLS version has a more spheric shape compared with the WEB-SL. The WEB-SL device is available in several diameters (from 4 to $9 \mathrm{~mm}$ ) and lengths (from 3 to 7 $\mathrm{mm}$ ), whereas the WEB-SLS device is available in several diameters (from 4 to $11 \mathrm{~mm}$ ) but only 1 length ( $4 \mathrm{~mm}$ ). The WEB device is deployed in the aneurysmal sac through $a \geq 0.027$ inch internal diameter microcatheter and can be fully retrieved until final detachment, and it is finally implanted by using an instantaneous, electrothermal detachment system contained in a hand-held controller.

The WEB system obtained the Conformité Européenne (CE) certificates for the Dual-Layer and the Single-Layer (SL/SLS) in March 2010 and March 2013, respectively. According to the 93/ 42/EC Directive, the WEB implant is a class III device. As of October 2015, the WEB device is not approved by the US Food and Drug Administration.

\section{Search Strategy and Search Terms}

The medical literature searches on the WEB device were undertaken up to September 2015 by using the MEDLINE, EMBASE, Cochrane Library, ClinicalTrials.gov, Database of Abstracts of Reviews of Effectiveness, and Health Technology Assessment data bases. The following key words were used in combination (by using "AND" and "OR"): "WEB," "Woven EndoBridge," "intracranial aneurysm (aneurysms)," "brain aneurysm (aneurysms).”

\section{Inclusion and Exclusion Criteria}

Type of Studies. All types of study designs published in all languages from January 2010 to September 2015 were included except letters, commentaries, preclinical studies, case reports, and case series with fewer than 10 patients.

Participants-Condition/Disease. All patients with no limitation of age with $\geq 1$ ruptured or unruptured bifurcation aneurysms were included.

\section{Intervention}

The intervention of interest was endovascular treatment with the WEB device (WEB-DL, WEB-SL, or WEB-SLS).

\section{Outcomes}

Feasibility was evaluated by the rate of technical success during the procedure. Effectiveness was evaluated by the percentage of patients with an adequate angiographic occlusion (total occlusion or neck remnant according to the 3 -grade Montreal scale ${ }^{15}$ ) at the different follow-up times. Safety was assessed by the mortality rate, the rate of patients with a modified Rankin Scale score of $>1$ (permanent morbidity), and the type and the percentage of complications at the different follow-up times.

\section{Study Selection Strategy and Data-Extraction Strategy}

Two authors (X.A. and B.G.) screened all identified bibliographic records for title/abstract and then for full text. The study flow and reasons for exclusion of full text articles were documented in a flow diagram (Fig 1), according to the Preferred Reporting Items for Systematic Reviews and Meta-Analyses (PRISMA) statement. ${ }^{16}$ Among full text articles assessed for eligibility, an analysis of overlapping study populations was performed to exclude studies in which the same patient had been described several times. Two authors (X.A. and B.G.) were responsible for detecting articles with duplicate published cases on the basis of the following criteria: name of authors, location of participating centers, and time of patients' selection. In case of doubt, publications were retrieved from the list.

\section{Individual Study Quality Assessment}

For the included studies that were uncontrolled, individual study quality was assessed by using a checklist published by the National Institutes of Health: "Quality Assessment Tool for Before-After (Pre-Post) Studies With No Control Group." "17 This 12-item checklist enables an assessment of uncontrolled studies and provides an overall quality rating. Quality assessment was performed independently by 2 authors (X.A. and B.G.).

\section{Data Synthesis}

Study, intervention, population, and outcome characteristics were summarized in the text and summary tables. Due to the presence of methodologic heterogeneity, data pooling was not appropriate.

\section{RESULTS}

\section{Search Results}

The flow chart presenting the process of identifying relevant articles is shown in Fig 1. After we removed duplicates, our search 


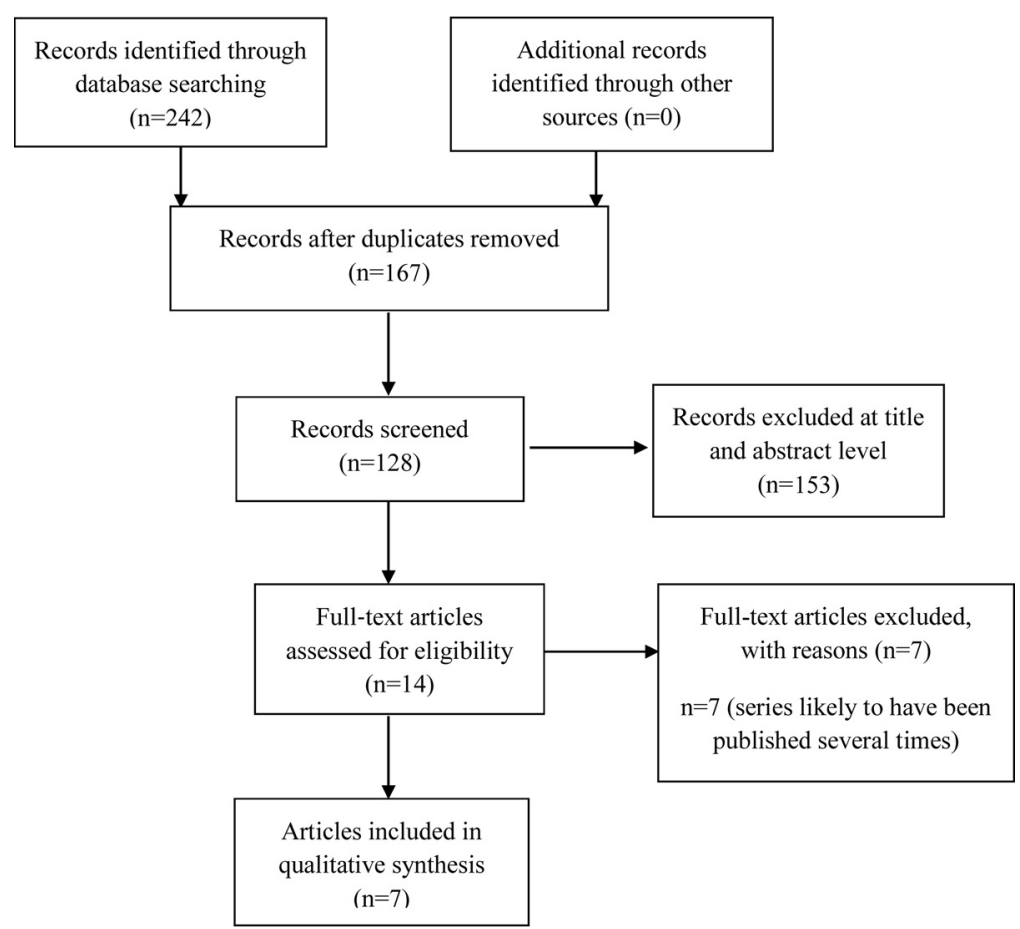

\section{Safety Data}

At last follow-up, the percentage of patients with an mRS score of $>1$ varied between $2.2 \%$ and $6.7 \%$. However, the average follow-up duration was limited (range, discharge to 6 months). The range of mortality rates at last follow-up was $0 \%-17 \%$. A mortality rate of $17 \%$ corresponded only to patients with ruptured intracranial aneurysms. ${ }^{18}$

The range of complication rates was $11 \%-14 \%$ in 3 studies and $22 \%-34 \%$ in 3 studies. Most complications consisted of thromboembolic events (between $31 \%$ and $81 \%$ of complications), with an incidence of 7\%-18\%. Apart from thromboembolic events, device problem-related events have been described, such as detachment, WEB protrusion, or a WEB stuck in the microcatheter. ${ }^{19}$ Intraoperative ruptures have been described rarely $(<2 \%){ }^{19}$
FIG 1. PRISMA study flow diagram.

identified 167 potentially relevant articles. One hundred fiftythree were excluded at the title and abstract level. Of the 14 articles identified, 7 were excluded because cohorts of patients were very likely to have been described several times or included in other cohorts. We finally presented the results of 6 studies ( 7 articles) that were all conducted in European centers (On-line Table). One article was the continuation of an already published article for the same study. We found no Health Technology Assessment report related to the WEB device.

\section{Patient and Aneurysm Characteristics and Feasibility of the WEB Device}

The number of patients was between 45 and 90, depending on the study. Aneurysm locations were mainly the middle cerebral artery, anterior communicating artery, or basilar artery. The neck size was $\geq 4 \mathrm{~mm}$ in most cases $(80 \%-100 \%)$, whereas the aneurysm size was mainly $<10 \mathrm{~mm}$. Five of the studies had selected patients with either ruptured or unruptured aneurysms, whereas 1 specifically reported outcomes of the WEB device on ruptured aneurysms. The implanted device was the WEB-DL in 2 studies and the WEB-SL in 1 study, whereas the other studies reported the use of the WEB-DL and the WEBSL. The rate of technical success leading to a WEB implantation varied between $93 \%$ and $100 \%$, depending on the study. Most interesting, the rate of additional treatment after the WEB deployment, whether anticipated or unplanned, was consistent between studies (8\%-15\%). It consisted of standard coiling, balloon-assisted coiling, or stent-assisted coiling. In most studies, authors reported the use of antiplatelet therapy (mainly single-antiplatelet therapy with aspirin or clopidogrel) after the procedure.

\section{Efficacy Data}

Most studies reported an angiographic outcome of limited duration (between 3.2 and 6 months). In those studies, the rate of adequate occlusion (total occlusion or neck remnant according to the 3 -grade Montreal scale ${ }^{15}$ ) varied between $65 \%$ and $85.4 \%$. In 1 study, ${ }^{20}$ the rate of adequate occlusion was reported at $84.2 \%$ after a mean duration of follow-up of 27.4 months.

\section{Quality Assessment}

Four studies were retrospective, whereas 2 were prospective. All were noncomparative. Studies had large heterogeneity in terms of methods for the assessment of outcomes (the presence of an adjudication committee; presence of a centralized core laboratory; differences in the timeframes for end points; and modalities for anatomic evaluations). Using the prespecified tool, the quality rating of studies was considered good in 2 studies; the others were rated fair or poor. The main limitations of studies were as follows: no prespecification of selection criteria for the study population; no justification of sample size; no clear definition of outcome measures; and no consistent assessment of outcome measures across all study participants. Consequently, the risk of bias was high in all except 2 studies.

\section{DISCUSSION}

Even though promising, the current knowledge on the WEB device is still limited. The WEB device emphasizes the great limitations of the current CE mark process in European countries. The current regulation on class III medical devices (2007/47/CE directive modifying the 93/42/CE) indicates that clinical evaluations are mandatory to comply with essential requirements needed for the CE marking. Most interesting, the first CE mark of the WEB device was obtained in March 2010, whereas the first report in humans was published in August 2011. ${ }^{12}$ Five years after the CE 
mark, a high number of articles on the WEB device have now been published. However, a high number were unfortunately excluded from our analysis because the same patients had likely been included in $>1$ published study or because the number of cases in that particular study was considered too small ( $<10$ patients).

Despite the very specific population (wide-neck bifurcation aneurysms in $\geq 80 \%$ of cases), the 6 analyzed studies ( 7 articles) are convergent in showing that the WEB endovascular procedure is feasible (successful placement between 93\% and 100\%), though several authors stressed that adequate patient selection and precise sizing of the device are key issues to achieving technical success. $^{21,22}$ Because the WEB placement is challenging, most of the experiences reported here were still performed within the learning curve. Although the number of observations was limited, Behme et $\mathrm{al}^{23}$ reported that patients obtained a more favorable angiographic result after a WEB procedure in their later experience in comparison with their earlier experience ( $75 \%$ of favorable angiographic outcome in 2014 versus $40 \%$ in 2012).

One study reported a complication rate of $34 \%$ in the most severe cases (ruptured aneurysms). ${ }^{18}$ An exception in this study, the range of procedural complication rates was $12 \%-25 \%$, and complications were mostly thromboembolic events with favorable outcome after treatment. The WEB treatment can therefore been considered as having an acceptable safety profile. The clinical outcome of patients treated with the WEB device is good (WEB treatment morbidity and mortality was between $2.2 \%$ and $6.7 \%$, and $0.0 \%$ and $17.0 \%$, respectively), but long-term data are clearly needed.

The currently available data on angiographic outcomes have shown promising results with immediate adequate occlusion rates (complete or neck remnant according to the 3-grade Montreal scale) of $65 \%-85 \%$ at $3.2-6$ months. One study reported a complete occlusion rate of $84.2 \%$ at 27.4 months. ${ }^{20}$ However, the follow-up concerned a limited number of cases (26 patients). Overall, long-term anatomic data on large prospective cohorts are needed to more accurately evaluate the efficacy of the WEB device. In fact, some authors have recently reported the risk of WEB compression with time. Cognard and Januel ${ }^{24}$ reported similar findings in a series of 15 consecutive patients. Compression of the WEB cage (12 WEB-DLs and 3 WEB-SLs) was observed at first follow-up (3-6 months) in 8 of $14(57.2 \%)$ and in an additional 3 of 7 cases $(42.8 \%)$ at the second control (18 \pm 3 months). The last angiography showed complete occlusion in 1 of 14 (7.2\%), neck remnant in 8 of $14(57.2 \%)$, and residual aneurysm in 5 of 14 $(35.7 \%)$ cases.

Sivan-Hoffmann et $\mathrm{al}^{25}$ also reported similar findings recently. Of 8 aneurysms included, worsening of the aneurysm occlusion was observed in 2 aneurysms (25\%) by compression of the WEB device. Although the recent article by Pierot et $\mathrm{al}^{26}$ showed that the aneurysm occlusion was stable between midterm and long-term follow-up, the risk of WEB compression and aneurysm recanalization must be carefully assessed. In addition, the WEB-DL and the WEB-SL/SLS seem to have the same safety profile at 1 month, but the impact of the modification of the WEB shape on long-term angiographic outcome should be further investigated. ${ }^{19}$

From a methodologic standpoint, most of the currently pub- lished articles have major limitations leading to a high risk of bias. First, the adjudication of end points (both adverse events and clinical outcomes) was performed in each participating center and not with an independent adjudication committee. Similarly, the angiographic parameters were mainly assessed by operators and not within an independent centralized core laboratory. In a recent meta-analysis, Rezek et $\mathrm{al}^{27}$ demonstrated that core laboratories tend to report higher rates of unfavorable outcomes compared with self-reporting centers. In our opinion, the results of angiographic outcomes reported with the WEB device should be analyzed with caution. Among the European studies, only 2 were conducted according to good clinical practices (the French Observatory ${ }^{19}$ and the WEB Clinical Assessment of Intrasaccular Aneurysm Therapy [WEBCAST] study ${ }^{26}$ ). No comparative data (either historical or prospective) are available to accurately determine the clinical and anatomic benefit of the WEB device in comparison with existing strategies. To our knowledge, no randomized clinical trial is either ongoing or planned to compare the WEB device with standard treatment, including endovascular coiling or surgical clipping. A prospective, multicenter, singlearm, cohort study (The WEB Intrasaccular Therapy Study [WEBIT], ClinicalTrials.gov Identifier: NCT02191618) is being conducted in the United States to finally obtain FDA clearance. ${ }^{28}$

\section{CONCLUSIONS}

Although the WEB device is a highly innovative technique for the endovascular treatment of bifurcation intracranial aneurysms with wide necks, to date, clinical data supporting the efficacy and safety of this new technology are limited to noncomparative cohort studies with extensive methodologic heterogeneity. According to the results of our literature review, WEB treatment of these intracranial aneurysms seems safe. However, no study comparing the safety and efficacy profiles of the WEB flow disruption technique with the balloon-assisted or stent-assisted coiling technique is available. The WEB device allows the treatment of wide-neck aneurysms with an acceptable adequate occlusion rate, but a not negligible rate of neck remnant. In addition, the risk of WEB compression and aneurysm recanalization must also be carefully assessed. Although it is promising for challenging wide-neck aneurysms, some issues are still unanswered regarding the benefit of the WEB long-term and its current positioning in comparison with existing strategies. The use of the WEB device may be considered in clinical situations with no acceptable therapeutic approach after discussion within a multidisciplinary team. Prospective controlled studies should be encouraged.

Disclosures: Francis Turjam—UNRELATED: Consultancy: Codman Neurovascular,* Medtronic*; Grants/Grants Pending: Medtronic*; Payment for Development of Educational Presentations: Codman, ${ }^{*}$ Balt.* * Money paid to the institution.

\section{REFERENCES}

1. Molyneux AJ, Birks J, Clarke A, et al. The durability of endovascular coiling versus neurosurgical clipping of ruptured cerebral aneurysms: 18 year follow-up of the UK cohort of the International Subarachnoid Aneurysm Trial (ISAT). Lancet 2015;385:691-97 CrossRef Medline

2. Zaidi HA, Montoure A, Elhadi A, et al. Long-term functional outcomes and predictors of shunt-dependent hydrocephalus after treatment of ruptured intracranial aneurysms in the BRAT trial:

AJNR Am J Neuroradiol 37:868-72 May 2016 www.ajnr.org 871 
revisiting the clip vs coil debate. Neurosurgery 2015;76:608-13; discussion 613-14; quiz 614 CrossRef Medline

3. Gory B, Turiman F. Endovascular treatment of 404 intracranial aneurysms treated with Nexus detachable coils: short-term and midterm results from a prospective, consecutive, European multicenter study. Acta Neurochir (Wien) 2014;156:831-37 CrossRef Medline

4. Ferns SP, Sprengers ME, van Rooij WJ, et al. Coiling of intracranial aneurysms: a systematic review on initial occlusion and reopening and retreatment rates. Stroke 2009;40:e523-529 CrossRef Medline

5. Gory B, Bonafé A, Pierot L, et al. Safety and efficacy of flow-diverter stents in endovascular treatment of intracranial aneurysm: interest of the prospective DIVERSION observational study. J Neuroradiol 2014;41:93-96 CrossRef Medline

6. Armoiry X, Paysant M, Hartmann D, et al. Interest of flow diversion prostheses in the management of unruptured intracranial aneurysms. Int J Vasc Med 2012;2012:654627 CrossRef Medline

7. Turjman F, Levrier O, Combaz X, et al. EVIDENCE trial: design of a phase 2, randomized, controlled, multicenter study comparing flow diversion and traditional endovascular strategy in unruptured saccular wide-necked intracranial aneurysms. Neuroradiology 2015; 57:49-54 CrossRef Medline

8. Gory B, Kessler I, Seizem Nakiri G, et al. Initial experience of intracranial aneurysm embolization using the balloon remodeling technique with Scepter C, a new double-lumen balloon. Interv Neuroradiol 2012;18:284-87 Medline

9. Gory B, Aguilar-Pérez M, Pomero E, et al. pCONus device for the endovascular treatment of wide-neck middle cerebral artery aneurysms. AJNR Am J Neuroradiol 2015;36:1735-40 CrossRef Medline

10. Gory B, Rouchaud A, Saleme S, et al. Endovascular treatment of middle cerebral artery aneurysms for 120 nonselected patients: a prospective cohort study. AJNR Am J Neuroradiol 2014;35:715-20 CrossRef Medline

11. Bartolini B, Blanc R, Pistocchi S, et al. "Y" and "X" stent-assisted coiling of complex and wide-neck intracranial bifurcation aneurysms. AJNR Am J Neuroradiol 2014;35:2153-58 CrossRef Medline

12. Klisch J, Sychra V, Strasilla C, et al. The Woven EndoBridge cerebral aneurysm embolization device (WEB II): initial clinical experience. Neuroradiology 2011;53:599-607 CrossRef Medline

13. Ding YH, Lewis DA, Kadirvel R, et al. The Woven EndoBridge: a new aneurysm occlusion device. AJNR Am J Neuroradiol 2011;32:607-11 CrossRef Medline

14. Papagiannaki C, Spelle L, Januel AC, et al. WEB intrasaccular flow disruptor-prospective, multicenter experience in 83 patients with 85 aneurysms. AJNR Am J Neuroradiol 2014;35:2106-11 CrossRef Medline

15. Raymond J, Guilbert F, Weill A, et al. Long-term angiographic recurrences after selective endovascular treatment of aneurysms with detachable coils. Stroke 2003;34:1398 - 403 CrossRef Medline

16. Moher D, Liberati A, Tetzlaff J, et al. Preferred Reporting Items for Systematic Reviews and Meta-Analyses: the PRISMA statement. PLoS Med 2009;21;6:e1000097

17. National Institutes of Health. National Heart, Lung and Blood Institute. Quality Assessment Tool for Before-After (Pre-Post) Studies
With No Control Group. 2014. http://www.nhlbi.nih.gov/healthpro/guidelines/in-develop/cardiovascular-risk-reduction/tools/before-after. Accessed October 9, 2015

18. Liebig T, Kabbasch C, Strasilla C, et al. Intrasaccular flow disruption in acutely ruptured aneurysms: a multicenter retrospective review of the use of the WEB. AJNR Am J Neuroradiol 2015;36:1721-27 CrossRef Medline

19. Pierot L, Moret J, Turjman F, et al. WEB treatment of intracranial aneurysms: feasibility, complications, and 1-month safety results with the WEB DL and WEB SL/SLS in the French Observatory. AJNR Am J Neuroradiol 2015;36:922-27 CrossRef Medline

20. Pierot L, Klisch J, Liebig T, et al. WEB-DL endovascular treatment of wide-neck bifurcation aneurysms: long-term results in a European series. AJNR Am J Neuroradiol 2015 Jul 30. [Epub ahead of print] CrossRef Medline

21. Bozzetto Ambrosi P, Gory B, Sivan-Hoffmann R, et al. Endovascular treatment of bifurcation intracranial aneurysms with the WEB SL/ SLS: 6-month clinical and angiographic results. Interv Neuroradiol 2015;21:462-69 CrossRef Medline

22. Gherasim DN, Gory B, Sivan-Hoffmann R, et al. Endovascular treatment of wide-neck anterior communicating artery aneurysms using WEB-DL and WEB-SL: short-term results in a multicenter study. AJNR Am J Neuroradiol 2015;36:1150-54 CrossRef Medline

23. Behme D, Berlis A, Weber W. Woven EndoBridge intrasaccular flow disrupter for the treatment of ruptured and unruptured wide-neck cerebral aneurysms: report of 55 cases. AJNR Am J Neuroradiol 2015; 36:1501-06 CrossRef Medline

24. Cognard C, Januel AC. Remnants and recurrences after the use of the WEB intrasaccular device in large-neck bifurcation aneurysms. Neurosurgery 2015;76:522-30; discussion 530 CrossRef Medline

25. Sivan-Hoffmann R, Gory B, Riva R, et al. One-year angiographic follow-up after WEB-SL endovascular treatment of wide-neck bifurcation intracranial aneurysms. AJNR Am J Neuroradiol 2015 Aug 20. [Epub ahead of print] CrossRef Medline

26. Pierot L, Costalat V, Moret J, et al. Safety and efficacy of aneurysm treatment with WEB: results of the WEBCAST study. J Neurosurg 2015 Sep 18. [Epub ahead of print] CrossRef Medline

27. Rezek I, Mousan G, Wang Z, et al. Effect of core laboratory and multiple-reader interpretation of angiographic images on follow-up outcomes of coiled cerebral aneurysms: a systematic review and meta-analysis. AJNR Am J Neuroradiol 2013;34:1380-84 CrossRef Medline

28. ClinicalTrials.gov. The WEB-IT Clinical Study. https://clinical trials.gov/ct2/show/NCT02191618?term $=\% 22 \mathrm{WEB} \% 22+\mathrm{AND}+\% 22$ aneurysm\%22\&rank=1 Cg. Accessed October 9, 2015

29. Lubicz B, Klisch J, Gauvrit JY, et al. WEB-DL endovascular treatment of wide-neck bifurcation aneurysms: short- and midterm results in a European study. AJNR Am J Neuroradiol 2014;35:432-38 CrossRef Medline

30. Caroff J, Mihalea C, Klisch J, et al. Single-layer WEBs: intrasaccular flow disrupters for aneurysm treatment-feasibility results from a European study. AJNR Am J Neuroradiol 2015;36:1942-46 CrossRef Medline 